\title{
El problema de la autenticidad de la filosofía latinoamericana
}

¿Por qué se ha cuestionado tanto, en los últimos tiempos, entre muchos intelectuales latinoamericanos la existencia de la filosofía en nuestras tierras?, ¿por qué se ha estimulado esta polémica? Si bien es cierto que ningún griego, italiano, alemán, ruso e inglés ha puesto en duda la autenticidad del pensamiento filosófico en sus respectivos países, parece ser que hay razones para que tal discusión haya tomado auge en esta parte del mundo en los últimos tiempos como continuidad de una vieja preocupación que tiene sus raíces en los inicios del siglo xx.

El problema del derecho a ser de la filosofía latinoamericana no constituye una simple cuestión de disquisiciones intelectuales, sino que tiene profundas raíces ideológicas y está aparejado al reconocimiento de todo el valor de la cultura latinoamericana. Por eso al adentrarnos en las múltiples posiciones sostenidas por diferentes autores respecto a este problema no podemos menos que tratar de delimitar lo que se persigue, con tan disímiles opiniones, no se reduce esto a una mera disputa académica — si bien por supuesto en gran medida lo es-, sino que rompe los marcos de los predios intelectuales para convertirse en un asunto que atañe a todo los humanos 
de estas latitudes que amam su cultura y que aspiran a verla justipreciada en el panorama de la cultura universal.

En la historia universal, una filosofía ha sido auténtica cuando no ha planteado simplemente ideas nuevas, sino cuando estas se han correspondido con las exigencias históricas de su momento en los diferentes planos, esto es, sociopolítico, económico, ideológico, científico. Así, la filosofía burguesa en la época de ascenso del capitalismo se caracterizó por su riqueza y plenitud. Sin embargo, en la época contemporánea aun cuando esta pueda mantener elementos de originalidad dada la multiplicidad de escuelas y problemas que plantea, en ocasiones ha perdido su carácter auténtico en tanto que sus ideas no siempre se han correspondido con la trayectoria del progreso social.

El análisis del pensamiento filosófico latinoamericano, de su originalidad y autenticidad debe tener en cuenta el retardo histórico que se produjo en esta región en relación con el desarrollo del capitalismo. Por ello, no debe resultar extraña la apropiación creadora por parte de pensadores latinoamericanos de corrientes de la filosofía universal y en especial de la europea que en otras latitudes podían resultar ya caducas y reaccionarias, pero que en nuestras circunstancias fueron desarrolladas y aprovechados aun de manera progresista sus núcleos racionales.

Indudablemente original ha sido desde el siglo pasado la reflexión de los filósofos latinoamericanos que se percataron de la necesidad objetiva de superar las relaciones de producción precapitalista y contribuyeron con sus ideas a ese fin. Pero mucho más originales y valiosas resultaron sus tempranas críticas a las nuevas relaciones de dominación y explotación que traía aparejado el capitalismo.

Con la época del imperialismo y la agudización de la situación socioeconómica de los países latinoamericanos, el pensamiento filosófico burgués ha tratado de buscar salidas originales que eviten la opción real presentada por la filosofía marxista y en ese sentido el problema de la originalidad ha cobrado mayor magnitud, pues aparecen nuevas variantes que pretenden conformar "nuevas filosofías" que rompan con todas las anteriores. Algunos de estos intentos, como la llamada "filosofía de la liberación latinoamericana", no dejan de ser originales en cuanto a sus formulaciones teóricas, pero se encuentran distanciados de una auténtica filosofía exigida por la transformación efectiva de la realidad latinoamericana. 
El primer problema que se plantea con relación a la autenticidad es de índole aparentemente semántico pues no existe unidad de criterios en cuanto a cómo denominar este pensamiento filosófico. Ante todo hemos sido víctimas de la prepotencia norteamericana al ser monopolizado por ellos hasta nuestro nombre común. Es frecuente encontrar obras con el título Filosofía americana (Marcuse, 1950), que se circunscriben a la historia de los Estados Unidos de América, ignorando por completo el pensamiento al sur del Río Bravo y sin hacer la menor referencia a la relatividad del término. Es como si dieran por aceptado universalmente que lo americano sólo les atañe a los hijos del coloso del norte. Muchos de los historiadores de la filosofía evaden ese término como aceptando que no nos pertenece, y que por tanto debemos siempre añadir el gentilicio "latina", "hispana" o "ibera" Esto quiere decir que entramos en desventaja en este debate, pues resulta incómodo hasta encontrar la designación a nuestra filosofía producto de la colonización cultural yanqui.

En ocasiones incluso se pone en duda la utilización de tales gentilicios y se prefiere emplear la preposición "en" para no tomar partido de antemano en esta controversia. De este modo se reconoce que hay indudablemente filosofía en esta parte del mundo, pero que no se ha ganado el derecho a ser apropiada y por tanto debe ser valorada como algo externo que vino a trasplantarse "en" este continente. En realidad tras estas aparentemente insignificantes cuestiones semánticas se esconde la subvaloración de nuestra filosofía y de su lugar en la historia.

Esta subestimación es frecuente en historiadores de la filosofía latinoamericana (Insua, 1959, pp. 27-31) ${ }^{62}$ que soslayan las cosmologías y cosmogonías de las culturas precolombinas y no les dedican la menor atención en sus estudios. Para estos, la filosofía llegó con Colón y ha seguido "llegando". Se ignora en verdad el nivel de desarrollo socioeconómico que alcanzaron dichas culturas, las cuales, como se ha debatido, pueden ser incluidas dentro del llamado por Marx modo de producción asiático, formación clasista

62 Véase: Insua, F. Historia de la filosofía en Hispanoamérica. Imprenta de la Universidad de Guayaquil, 1945. Uno de los pocos historiadores que le dedican atención particular el pensamiento precolombino es el ecuatoriano Alfredo Carrillo en su obra La trayectoria del pensamiento filosófico en Latinoamérica. Editorial Casa de la Cultura, Quito, 1959, pp. 27-31. 
temprana en la que necesariamente se produjo un pensamiento filosófico embrionario que se emancipaba cada vez más de la tutela religiosa y que, si bien aún se expresaba en forma de mito - no olvidemos que también en Grecia el mito fue cuna de la filosofía-, ya conformaba una cosmovisión orgánica y en esencia racional del mundo, elemento este que, como sabemos, distinguen al pensamiento filosófico.

¿Acaso no hay racionalidad en el hilozoísmo y el transformismo incaico, que aseveraba las metamorfosis constantes de animales, plantas, piedras y humanos? Esa consustancialidad la constatamos en el oriente antiguo y nadie duda - excepto los eurocentristas - que allí se desarrolló la filosofía mucho antes que en la antigua Grecia. No se puede objetar por otro lado que en el Popol Vuh las fuerzas autónomas de la naturaleza determinaron la creación del mundo y que, si bien se habla de creadores, se conciben estos como potencialidades inherentes al propio mundo y no venidos desde fuera. Así, al igual que en otras cosmogonías orientales y griegas, se concibe el agua como elemento eterno y primigenio. "Esta es la relación de cómo todo estaba en suspenso, todo en calma, en silencio, todo inmóvil, callado y vacía la extensión del cielo." Así se inicia este libro común de los quichés que prosigue: "No había nada que estuviera en pie, solo el agua en reposo, el mar apacible, solo y tranquilo" (Popol Vuh, 1975, p. 3).

Esto es una confirmación más de que el pensamiento filosófico comienza a alcanzar su carta de ciudadanía allí donde empieza a enfrentarse a las creencias religiosas, aquellas que sitúan el origen de todo lo existente en fuerzas celestiales y sobrenaturales. En tanto que el humano se considera producto de algo exterior a la naturaleza, está inmerso en el terreno de la religión; pero cuando se cuestiona la existencia de todo y busca sus raíces en el autodevenir de la naturaleza, por más que busque nombres propios para denominar a esas fuerzas, está dejando a un lado ese campo e incursionando en el fecundo universo de la filosofía. Una vez que da ese paso se acerca más a la toma de conciencia de su especificidad y de su lugar en el mundo.

La filosofía le concede al ser humano lo que la religión le niega: la comprensión de sus capacidades, tratando de arrancarle la falsa imagen que él tiene de sí mismo. Por eso cuando un pueblo como el quiché afirma que "no habrá gloria ni grandeza en nuestra creación y formación hasta que exista la criatura humana, el hombre formado” (Popol Vuh, 1975, p. 5), está 
filosofando de algún modo, porque está situando al humano en su justa dimensión como valor supremo de todo lo existente.

Sería estéril buscar sistemas filosóficos propiamente en los pueblos precolombinos. Tal vez la devastación de la conquista es responsable de la pérdida de otros testimonios que prueben la riqueza de la cosmovisión amerindia. Pero los elementos con que contamos indican que si bien no teníamos una Atenas en América a la llegada de los españoles, sí contábamos con pueblos con suficiente grado de madurez socioeconómica e intelectual como para elaborar criterios políticos, jurídicos (Guadarrama, 2014b. pp. 330-356) y filosóficos del mundo (Dussel, 2009). Por otro lado, el hecho de que estos no tuvieran una gran intercomunicación cultural que les hiciera formar una amplia comunidad no puede constituir de ningún modo un argumento, como en ocasiones se pretende, para soslayar el valor de sus ideas filosóficas.

La preocupación por el derecho a existir de la filosofía latinoamericana parece que comenzó a fortalecerse en la primera mitad del siglo XIX, unido al proceso de toma de conciencia nacional que vitalizan las guerras emancipadoras del colonialismo español. Eso no significa que con anterioridad pensadores criollos no hayan dejado huella en la historia de nuestras ideas; pero lo cierto es que con los españoles vino la escolástica, y llegaron las ideas de Tomás de Aquino, Duns Scotto y el español Francisco Suárez, por lo que el pensamiento filosófico en el nuevo mundo se vería controlado por la teología, como había sucedido desde centurias anteriores en la Europa medieval. Entonces, ¿qué originalidad o qué autenticidad podemos intentar encontrar aquí en la filosofía, si en la propia Europa el pensamiento filosófico había sufrido el desconcierto que necesariamente una filosofía como la escolástica producía al supeditar la razón a la fe? Tal vez entre los aportes de América a la filosofía universal en ese período haya estado la propia existencia de América; su cultura, costumbres, instituciones, y demás. Tanto Moro como Montaigne, se inspiraron en el nuevo mundo en sus concepciones sociopolíticas.

Los temas de la condición humana de los indígenas americanos (Guadarrama, 2014a), del derecho a su conquista, entre otros, motivaron innumerables discusiones filosóficas. Nuestra filosofía en ese periodo de destrucciónde la cultura aborigen radicaba en nuestra propia subsistencia. 
La razón de ser de nuestra filosofía estaba en juego porque se debatía entonces nuestra propia razón de ser.

Una vez que se había planteado a los pueblos latinoamericanos la tarea de romper con la tutela colonial y emprender la marcha política independiente afloró la problemática de la filosofía original. Uno de los primeros en reconocer la existencia de este problema fue el argentino Juan Bautista Alberdi, quien criticaba en 1842 la ausencia de una filosofía latinoamericana y planteaba a la vez la necesidad de crearla. Solicitaba una filosofía que no fuera abstracta sino vinculada a los problemas concretos de nuestros pueblos. Muy justificadas eran sus pretensiones de lograr para esta cultura lo que otras más avanzadas ya podían abiertamente ostentar, pero ¿no implicaba tal postura el inicio de la difusión de ese criterio tan arraigado después, de que hemos sido incapaces de filosofar?, ¿no significaba esto ignorar la labor filosófica de pensadores como Benito Díaz de Gamarra, en México; Félix Varela, José de Luz y Caballero, Enrique José Varona (Guadarrama, y Tussel, 1987), José Martí (Guadarrama, 2015a), en Cuba; Andrés Bello, en Venezuela; Sarmiento y el propio Alberdi, en Argentina, entre otros? El espíritu antimetafísico típico del positivismo llevó a Alberdi a tales consideraciones, y quizás la hostilidad manifiesta del positivismo mismo contra la filosofía hizo que dudara en aquellos momentos de la existencia de esta en América y sugiriera la búsqueda de una filosofía práctica para resolver nuestros problemas inmediatos. No obstante tales limitaciones y sus dudas sobre la posibilidad de una filosofía latinoamericana, no deja de ser meritoria la toma de conciencia por la necesidad de desarrollar sólidas culturas nacionales que se propusieron Alberdi, junto a Sarmiento, Lastarria en Chile, Montalvo en Ecuador y otros.

El tema de la autenticidad de la filosofía latinoamericana estará presente en todas las generaciones de pensadores posteriores, pero nunca constituirá una preocupación central de su quehacer intelectual. Emergió una que otra vez en la obra de Varona, Hostos (Guadarrama y Maddaloni 2016) e Ingenieros, como representantes del positivismo tardío, así como entre la generación antipositivista: Antonio Caso, José Vasconcelos, en México; Alejandro Korn, en Argentina; Carlos Vaz Ferreira, en Uruguay; Alejandro Deustua, en Perú; pero será a partir de la década de los años cuarenta del pasado siglo xx que se convertirá en uno de los ejes centrales y obligados de diferentes discusiones que motivarán no solo múltiples 
obras al respecto, sino hasta eventos internacionales, como el celebrado en La Habana en 1953, con motivo del centenario del nacimiento de José Martí, cuya temática central incluía este tema.

Parecía que los pensadores latinoamericanos se habían cansado de tanta tutela intelectual de Europa, de ser la caja de resonancia de cuanta corriente o escuela apareciese en el viejo mundo, que había llegado la hora de nuestra emancipación cultural y que bastaba ya de supeditación filosófica. Se presentaba como un noble empeño encaminado a rescatar nuestros valores y a proclamar nuestro lugar en el concierto filosófico mundial. Todos estos ingredientes forman parte real de esta nueva actitud, pero el hecho de la prolongación y ensanchamiento de esta polémica fue revelando cada vez más dónde descansaba su móvil sustancial. Se ha intentado buscar una filosofía latinoamericana para evadir la creciente propagación de la filosofía marxista en este continente. El nacimiento del sistema socialista mundial constituyó un suceso aparentemente lejano, pero que en verdad se hizo sentir en esta renovación de las preocupaciones. El despliegue del socialismo en este continente con el triunfo de la Revolución Cubana y su consiguiente influencia sobre América Latina conformaría a su vez un momento significativo para revitalizar esa polémica.

El proceso de profundización de la contradicción fundamental de nuestra época entre el capitalismo y el socialismo se refleja directamente en el pretendido apartidismo filosófico - el cual no debe ser identificado con apartidismo político-, que se pone de manifiesto en algunos representantes de la filosofía latinoamericana. Muestra de esa actitud la encontramos en el libro ¿Existe una filosofía de nuestra América? del destacado intelectual peruano Augusto Salazar Bondy (1969), en el que afirma:

Puesto que nuestros pueblos solo saldrán de su condición rompiendo los lazos que los tienen sujetos a los centros de poder y manteniéndose libres con respecto a toda otra sujeción que paralizaría su progreso, se hace claro que la filosofía que hay que construir no puede ser una variante de ninguna de las concepciones del mundo que corresponden a los centros de poder de hoy, ligadas como están a los intereses y metas de esas potencias (p. 127).

Es evidente que esta constituye una nueva variante del "despreciable partido del término medio en filosofía” (Lenin, 1965, T. XIV, p. 337), que Lenin 
de modo concluyente refutó. Como puede apreciarse, en la tesis de Salazar Bondy se pretende encontrar una concepción filosófica del mundo que no sea en esencia ni el idealismo, ni el materialismo. Aun cuando no los denomine así. Es un rasgo común de algunos filósofos latinoamericanos no llamar a las cosas por sus verdaderos nombres a la par que eluden el reconocimiento de la lucha entre el materialismo y el idealismo.

El vínculo entre la filosofía que se busca y la ideología que se sostiene es marcado, porque no solo se está en pos de una "tercera" filosofía, sino también de una "tercera" ideología "tercermundista". Así en Salazar Bondy, como en otro sobresaliente estudioso de la filosofía latinoamericana, el mexicano Leopoldo Zea, están presente una elogiable identificación con las aspiraciones emancipadoras de los países subdesarrollados del mundo. Es justo reconocer esas coincidencias con las causas de los pueblos explotados del mundo; sin embargo, en ningún momento se precisan cuáles son las causas reales de ese subdesarrollo, y no las encuentran, porque no se plantea conscientemente su búsqueda. Capacidad, poseen suficiente para ello, pero no llegan a desentrañar y divulgar la esencia explotadora del imperialismo y, en particular, el norteamericano como la raíz última de la situación dependiente de los países latinoamericanos. En sus obras afloran críticas a algunos rasgos de la plutocracia yanqui, pero no van más allá que a apuntar una verdad archiconocida, incluso entre quienes no tienen formación marxista.

Sorprenden realmente las frases de estos intelectuales en su formulación por su lenguaje revolucionario. Así, un pensador como Zea (1969), a quien indudablemente podemos considerar como un intelectual de ideas progresistas, sostiene que:

La autenticidad de nuestra filosofía no podrá así, provenir de nuestro supuesto desarrollo, como tampoco le ha venido a la filosofía occidental, en cuyos creadores se hace ahora consciente la enajenación. Esta vendrá de nuestra capacidad para enfrentarnos a los problemas que se nos plantean hasta sus últimas raíces tratando de dar a los mismos la solución que se acerque más a la posibilidad de la realización del nuevo hombre. Naturalmente, dentro de estas soluciones estará la de una revolución que anule las trabas que impiden la posibilidad de este hombre, pero esta solo será consecuencia de la autenticidad de nuestro pensamiento sobre la realidad que ha de ser transformada. 
La autenticidad no ha de ser consecuencia de esa posible revolución social, política y económica sino la base de su posibilidad. Auténtica no solo ha de ser la filosofía que surja con el establecimiento de una nueva sociedad, auténtica tendrá que serlo, también, la que haga consciente nuestro subdesarrollo y señale las posibilidades de su vencimiento y la forma de vencerlo (p. 153).

Ahora bien, ¿cuál a su juicio es esa filosofía? Considera que la de Salazar Bondy ya es auténtica, pero la dificultad radica en determinar los principios básicos de esa filosofía, especialmente las tesis esenciales que la hagan científica y revolucionaria: científica, porque debe demostrar a través de los hechos la realización de sus postulados; revolucionaria, porque va a indicar la transformación cualitativa que se llevará a efecto y explica cómo alcanzarla. En verdad ninguna otra filosofía que no sea la concepción materialista de la historia ha demostrado satisfacer esos requisitos. Prueba fehaciente de cómo una filosofía puede arrancar del atraso socioeconómico es el ejemplo de la Unión Soviética, si se compara la situación de Rusia antes de 1917 y su desarrollo posterior — independientemente de su posterior derrumbe-, y así como la Revolución Cubana, que a pesar del bloqueo yanqui ha ido rompiendo las trabas del subdesarrollo.

¿A qué tipo de nueva sociedad aspira Zea?, ¿dónde, se hará realidad la filosofía latinoamericana auténtica? En varias de sus obras de fines del siglo $\mathrm{xx}$ trató de ofrecer respuesta sobre esa sociedad que anhelaba con la llamada "filosofía de liberación" (Zea, 1976, pp. 58-65) cuando señalaba:

Pienso en un mundo plenamente libre, libre, pero responsable de esta libertad. Un mundo en el que el hombre no sea más ni lobo, ni oveja del hombre, ni tiburón, ni sardina. Mundo en el que el hombre se reconozca como tal, no a partir de la imagen que se haya hecho de sí mismo, sino de la imagen que le ofrezcan los otros, del reconocimiento de quienes son sus semejantes: ¿Socialismo? Por supuesto, pero en el que el hombre como libertad pueda expresarse sin que esta expresión implique el manipuleo de otros (Zea. 1976, p.51).

Su concepto de libertad resultaba algo abstracto, ya que trataba de situarse por encima de las clases sociales y de sus ideologías, que delimitan la concreción de libertad. Por ello no se debía inferir que su aspiración fuese el 
socialismo como realización de la clase obrera, ya que se desvirtúa en sus análisis la existencia de las clases. Por otro lado es común a la tergiversación de los términos como ocurre con la palabra socialismo y hasta comunismo, que se emplean con las más diferentes acepciones. Hoy son más válidas que nunca aquellas palabras de Lenin que indican: "Quien después de la experiencia de Europa y de Asia, hable de una política que no sea de clase y de un socialismo que no sea de clase, merece simplemente que se le meta en una jaula y se le exhiba junto a un canguro australiano" (Lenin. p. 575).

En verdad Zea no delimitaba cuales serían las características fundamentales de esa sociedad futura que, según él, reclamaba la auténtica filosofía latinoamericana. No resultaba entonces difícil reconocer tras ella las aspiraciones de la burguesía nacional frustrada que en Latinoamérica se ha visto asfixiada por el imperialismo y con el cual mantiene abiertas contradicciones, pero su opción de desarrollo no puede naturalmente ser el socialismo porque este significa su negación dialéctica. Así se ponían de manifiesto las raíces ideológicas del deseo de autenticidad en el pensamiento filosófico latinoamericano. Si se buscaba una filosofía para la transformación, ¿por qué razón habría de pensarse que sería una sumisión más de la cultura latinoamericana respecto a la europea?

Zea parece llegó a percatarse de la aplicación del marxismo a las condiciones de América Latina, ${ }^{63}$ pero lo presenta como una nueva adaptación de una corriente filosófica europea más a las circunstancias de este continente. No expresa de ninguna manera sus criterios sobre la efectividad de las soluciones que esta ofrece. En realidad, en él se aprecia una marcada insatisfacción

63 "El marxismo alcanza no solo una interpretación latinoamericana sino que es adaptado a la realidad propia de esta América. Ejemplo teórico de este hecho lo es el marxismo de José Carlos Mariátegui y en la praxis lo es el marxismo de Ernesto Che Guevara y de Fidel Castro". Zea, L. La filosofía americana como filosofía sin más, México. 1969. Editorial Siglo XI. p. 74. Zea evidencia una comprensión algo más acertada de la validez histórica universal del marxismo aun cuando establece una injustificada superación ente la teoría y la práctica política de estas significativas personalidades aparte de considerarla como una filosofía más para la realidad latinoamericana. De ningún modo se plantea que el marxismo sea la filosofía que da respuesta efectiva, a la situación de la realidad latinoamericana como parte del mundo. Para él, el marxismo es un instrumento más al igual que otras filosofías, la fenomenología, etc., que debe ser utilizado. Para Zea la auténtica filosofía latinoamericana debe ser filosofía a secas. "filosofía sin más", estos es, un filósofo que por añadidura será latinoamericano pero que sin que se lo proponga. 
con la realidad latinoamericana de su época y en cierta forma con su pasado, así como con su reflejo filosófico, por eso busca en los valores de ese pasado el punto de partida para lograr una filosofía de emancipación social que le otorgue autenticidad a la filosofía latinoamericana. Pero toda su bondadosa fe en esa venidera filosofía y en esa sociedad futura imprecisa la hace descansar en soluciones sobre los pilares de autoconsciencia, revelando una marcada influencia hegeliana en su concepción del mundo e indicando una vez más la clásica incapacidad del idealismo filosófico para transformar el mundo.

Otro que reclama una "filosofía de los pueblos pobres, una filosofía de liberación humana mundial” (Dussel, 1973, p. 11), si bien en un sentido algo diferente al de Zea, es el argentino Enrique Dussel, quien, poniendo de manifiesto lo que pudiéramos llamar un hegemonismo filosófico latinoamericano, expresaba hace algunos años sus criterios regionalistas y sobrevaloradores de nuestra filosofía, tan peligroso como los criterios contrarios. Dussell sostenía que "la filosofía latinoamericana, es entonces un nuevo momento de la historia de la filosofía humana, un momento analógico que nace después de la modernidad europea, rusa y norteamericana, pero antecediendo a la filosofía africana y asiática postmoderna que constituirán con nosotros el próximo futuro mundial" (Dussel, 1973, p. 56). De estas palabras se desprendía claramente la marcada pretensión de evadir la contradicción fundamental que caracterizaba la época de la guerra fría.

Los extremos se tocan, por eso esta hiperbolización de la filosofía latinoamericana encierra en última instancia tomar por dada la sumisión actual de esta. De ahí sus reproches a las generaciones anteriores de pensadores latinoamericanos, al haber aceptado la dominación foránea y haber difundido ese espíritu sumiso. Esa añoranza de una futura dominación de nuestro pensamiento sobre el europeo actual, en algún momento presuponía la aceptación de que estabamos dominados por filosofías extrañas a nuestro ser y que no nos había llegado el turno de ser los dominadores, o sea, que ya vendría el momento en que fuésemos los amos de la filosofía. Siempre se debe recordar aquella profunda sentencia de Rousseau que indicaba "el mismo que se considera amo no deja por eso de ser menos esclavo que los demás" (Rousseau, 1973, p. 605). La filosofía que se pretende imponer sobre las demás apoyadas cualquier tipo estrecho regionalismo o etnocentrismo, en circunstancias nacionales o particulares de un pueblo o raza, como el nazismo, está condenado al fracaso como la historia demuestra. 
Esta concepción cíclica que planteaba Dussel, en aquellos época de los años setenta e inicios de los ochenta y que posteriormente abandonó, según la cual la filosofía dejó atrás la etapa fisiológica griega, la teológica medieval, logos-lógica moderna y ahora se prepara para entrar en la "primera edad antropológica”, de la que se encargará la filosofía latinoamericana, resultaba bastante infundada, ya que en la historia de la filosofía el problema humano siempre ha estado presente en mayor o menor grado, simultáneamente en las preocupaciones cosmológicas, cosmogónicas, teológicas, y demás. De lo contrario la filosofía habría perdido su esencia como concepción general del mundo y se hubiese quedado en los estrechos parámetros de un saber particular. El hecho real que en determinadas épocas haya prevalecido un problema sobre los demás no significa que los demás hubiesen desaparecido.

Uno de los primeros en haber planteado la idea del inicio de la "era de la filosofía latinoamericana” fue el filósofo mexicano José Vasconcelos en una conferencia pronunciada en 1930 en el Instituto Hispanocubano de Cultura de La Habana, en la que invita a aprovechar solamente los métodos de las viejas culturas ya estériles como la alemana. Este criterio tomó fuerza y se mantuvo también en la metafísica concepción cíclica del desarrollo filosófico del peruano Francisco Miró Quesada, para quien "el filósofo latinoamericano está siempre pensando en el futuro". Filosofía pensando que todavía no hace verdadera filosofía, que está en su época de formación, pero que algún día llegará a hacer "verdadera filosofía". La filosofía latinoamericana tiene esencia prospectiva en un proyecto. La filosofía occidental es una realidad y un pasado (Miró, 1953, p. 125). Nótese en primer lugar, cómo se presupone en definitiva la no existencia de la filosofía latinoamericana, si bien en obras posteriores Miró acepta ya su realidad y a la vez se refleja el frecuente complejo de inferioridad de muchos pensadores latinoamericanos al tratar de medirse siempre por lo europeo.

Zea también compartió esta tesis cíclica, aunque indicando que no debía considerarse inferior nuestra filosofía "porque esta madurez por alcanzar es un signo de su posibilidad que ya no poseen las culturas logradas, maduras, cumplidas" (Zea, 1976, p. 16). Pero lo esencial en esta posición es que si bien se reconoce la indiscutible herencia que deja Europa sobre la filosofía latinoamericana, se parte de una visión errónea del desarrollo histórico, pues se concibe un proceso cíclico de sustitución de culturas al estilo de Toynbee y de Spengler, que la propia historia se ha encargado de desmentir. 
Esta forma de sustitutismo establecía un abismo entre el pasado y el futuro, y no se percataba de la imposibilidad de concebir proyectos que no presupongan una realidad dada ya que toda nueva cualidad encierra en su ser los elementos superados y siempre presentes de la anterior. En verdad este rechazo a la contemporaneidad europea no constituía un enfrentamiento a todo lo proveniente del viejo mundo, sino que descansaba en última instancia en el marcado interés de obviar la filosofía que ha intentado sintetizar toda esa herencia europea y universal, la marxista, a la cual se intenta ubicar en la misma situación de crisis que las demás expresiones de la filosofía actual. Por supuesto que el marxismo ha experimentado y aún experimenta determinadas crisis (Guadarrama, 1989b. pp. 184-192), pero su naturaleza es muy diferente a la de otras corrientes filosóficas.

La mayoría de los investigadores de la filosofía latinoamericana coinciden en señalar como elemento de su originalidad, la vocación humanista de esta. Unido a la problemática de la existencia o no de la filosofía latinoamericana ha estado siempre presente el tema de su preocupación antropológica, especialmente el de la condición humana,${ }^{64}$ mucho más

64 “Cuál concepto es más apropiado para una adecuada comprensión del lugar y papel del ser humano en el devenir del mundo: naturaleza humana, esencia humana o condición humana? ¿Por qué razón puede ser más apropiado uno que otro para un mejor análisis del ser humano? ¿O en qué medida podrían complementarse si se articulan debidamente?

Los estudios referidos a la cuestión de la condición humana, desde las primeras manifestaciones del pensamiento recogidas por la historia hasta nuestros días -independientemente de la utilización o no de dicho término- han evolucionado paulatinamente en la misma medida que también el propio ser humano ha ido cambiando en su relación con la naturaleza, con sus congéneres y consigo mismo.

De manera que resulta en ocasiones algo difícil presuponer que necesariamente el ser humano se perfecciona constante y progresivamente, especialmente cuando se observa la actitud de algunos especímenes que aunque tengan figura humana, y se comuniquen como otros seres humanos a veces resulta difícil aceptar que piensen y actúen racionalmente, lo cual no quiere decir que tales actitudes misantrópicas de ciertos individuos, a los que se dificulta considerar como humanos, hayan sido y continúen siendo los predominantes en el género humano. Admitirlo implicaría en algún modo pensar que la humanidad ha involucionado en lugar de haber progresado en sentido general durante su ya larga existencia.

Demostrar mediante una acuciosa investigación que la intelectualidad latinoamericana del pasado siglo $\mathrm{xx}$ se suma a la tendencia general observada en otras latitudes y épocas, pero especialmente en la modernidad, que confía en el perfeccionamiento del ser humano, de su condición que lo distingue del mundo animal, aunque este de 
apreciable sobre todo en el siglo $\mathrm{xx}$ (Proyecto internacional de investigación www.ensayistas.org/critica/generales/C-H/).

Algunos investigadores, como el argentino Aníbal Sánchez Reulet, olvidando el valor de nuestra herencia filosófica anterior, considera que "el cultivo de la filosofía, con un sentido creador y original es un hecho relativamente reciente en América Latina” (Sánchez Reulet, 1949, p. 11), y sitúa en este siglo su verdadero arranque, caracterizado por su "hondo sentido humanista" $(1949$, p.18). Sánchez no duda de que hoy en día "al menos desde el punto de vista histórico y sociológico, existe una filosofía o un movimiento filosófico de América" (Sánchez Reulet, 1953, p. 45). A él no le preocupa tanto la originalidad de este movimiento, puesto que con razón piensa que "no hay problemas filosóficos típicamente americanos, América tiene problemas políticos, sociales y económicos que son hasta cierto punto específicos, pero los problemas filosóficos serán siempre comunes a todos los hombres, lo mismo que las soluciones" (Sánchez Reulet, 1953, p. 146) ahora bien, al denotar la vocación humanista de nuestros pensadores se trata de un modo indirecto de dejar sentado un rasgo peculiar

algún modo este subsumido y superado en él, no constituye una labor asépticamente científica y sin contaminaciones ideológicas.

Aquellos que se aferran a la idea de la existencia de una presunta inamovible e imperfectible naturaleza humana egoísta, individualista, explotadora, discriminatoria, etc., por supuesto que pueden encontrar algunos argumentos para justificar desde concepciones discriminatorias, racistas y fascistas, hasta las más recientes posturas neoliberales, actualmente de capa caída tras los recientes desastres financieros del capitalismo mundial.

Por el contrario, pareciese que la progresiva fermentación de un ideario de corte básicamente humanista que se fue consolidando en el subcontinente en el transcurso del siglo xx, en dialéctica recepción heredera de lo mejor del pensamiento ilustrado y en particular decimonónico, sirvió de premisa y contribuyó de algún modo también a la preparación ideológica de las progresivas transformaciones que emprenderían los pueblos latinoamericanos especialmente a fines de aquel e inicios del siglo xxi. Tendrían que pasar algunos años de maduración filosófica, ideológica y cultural para se llegase a reconocer la paciente y vital labor desplegada por varias generaciones intelectuales y políticas latinoamericanas, que no obstante su diversidad y heterodoxia fueron depositando valiosos y vitales granos de arena en la construcción y realización de un humanismo práctico, que no se limitó a revertirse de manera exclusiva sobre los pueblos latinoamericanos, sino que, por el contrario, solidariamente a varias regiones del mundo". Guadarrama, P. Pensamiento Filosófico Latinoamericano. Humanismo, método e historia. Universitá degli Studi di Salerno-Universidad Católica-Planeta. Bogotá. Tomo III. 2013. p. 427 
y diferenciador de esta filosofía, el de eludir las cuestiones cosmológicas, en las que las ciencias naturales resultan un poderoso instrumento auxiliar, dado el limitado desarrollo de las ciencias naturales en estos pueblos.

No se debe negar que el nivel científico-técnico de los países latinoamericanos no puede compararse con el de Europa o Norteamérica. Los pueblos de Nuestra América han sido víctimas de las consecuencias negativas que trae aparejado el desarrollo desigual del capitalismo, pero esto no puede llevarnos a pensar que hemos estado al margen del pensamiento científico universal ya que nuestros modestos valores han dejado sus huellas en esta cultura y, a la par los filósofos latinoamericanos no han vivido de espaldas al quehacer científico mundial, incluso muchos han sido propulsores y no simples divulgadores, como el paleontólogo argentino Florentino Ameghino o el naturalista cubano Felipe Poey. De ahí que no se debe aceptar que el reconocimiento del carácter esencialmente humanista del pensamiento filosófico latinoamericano (Guadarrama, 1993, pp. 49-63) obligue a diluir en lo poético la riqueza de las ideas filosóficas surgidas en éste continente.

Hay quienes han llegado a inferir que esa propensión literaria y humanista de nuestro pensamiento ha sido de signo positivo, como el cubano Rafael García Bárcena, quien en 1946 sostenía que después de la Segunda Guerra Mundial el foco de la cultura mundial se había trasladado de Europa a América, y dado que según él los temas de la vida, los valores y el humanismo se habían convertido en los principales de la filosofía de ese momento, por tanto "ese literaturismo, que en el fondo alude a una vida efectiva, rica en disposiciones estéticas, puede ser un índice de idoneidad para el cultivo de la filosofía" (García, 1949. No. 1. p. 34), filosofía que se les encargaba desarrollar a los pensadores latinoamericanos.

En verdad somos amantes del lenguaje literario como cualquier otro pueblo del mundo, pero esto no implica que hayamos eludido el lenguaje científico o los problemas que plantea el desarrollo de la ciencia. "Por ello no es válido tampoco el planteamiento o que solo podrá haber una auténtica y perdurable filosofía iberoamericana en la medida en que sus cultivadores profundicen en la problemática suscitada por la revolución científica que se ha producido en el siglo xx" (Castro, 1953, p. 115) como aseguraba el cubano Máximo Castro Turbiano, en una discusión sostenida en 1953, pues ni la filosofía latinoamericana, ni la europea, ni la de ninguna otra parte puede reducir su objeto a los problemas que efectivamente 
plantea la actual revolución científico-técnica. Su radio de acción siempre será mucho más amplio que el que intentan atribuirle los criterios positivistas renovados, por ello, si bien estos problemas estarán presentes en toda meditación filosófica contemporánea, lo haría en la medida en que se analicen junto a las demás interrogantes inherentes a la filosofía. Si la razón que anima este argumento es la necesidad de "una filosofía que sea capaz de ofrecernos una visión unitaria de la realidad" y sustituye adecuadamente a la ya caduca concepción mecánica de la naturaleza (Castro, 1953 , p. 115) como este afirmaba, resulta ya infundada, pues el materialismo histórico hace mucho que superó esa vieja concepción metafísica del mundo, y cada descubrimiento significativo en las ciencias naturales ha encontrado en él su adecuada interpretación, como lo demuestra la labor de Lenin al producirse la llamada "crisis de la física".

La subestimación de las posibilidades intelectuales de los latinoamericanos ha llegado a los extremos de plantearse su falta de capacidad para filosofar, como ha asegurado el boliviano Manfred Kempf Mercado (Kempf, 1958, pp. 35-42) y no han faltado las interpretaciones irracionalistas como las de Waldo Ross, quien afirma que el "americano es poco dado a entregarse a lo inteligible, propio de las esencias y menos aún a rendirse frente a los hechos que se le presentan a su paso. Hay cierta magia nuestra, que nos hace pensar que en el fondo, poseemos la vara milagrosa capaz de cambiar tarde o temprano el giro de nuestro destino" (Ross, 1954, p. 7). El carácter contraproducente de esta tesis se pone de manifiesto, como el del irracionalismo en general, en que siempre ha llevado en su seno la justificación de las acciones más negativas, no solo al negar la unidad histórica y cultural de los pueblos latinoamericanos al concebirlos como un "mosaico irracional", sino también al criticar infundadamente lo que él considera que ha sido nuestro "servilismo". Por eso recomienda que la filosofía latinoamericana debiera comenzar con un elogio a la barbarie, "Ser bárbaro es ser joven y ser dueño del futuro y libre de cadenas” (Ross, 1954, p. 23). De este modo su honda inspiración nietzscheana lo empuja a buscar una filosofía del desquite, como si quisiera dejar empequeñecidos los bárbaros actos de la conquista y colonización, así como los de la dominación imperialista actual. Esta receta misantrópica, emparentada en definitiva con el hegemonismo que analizamos anteriormente, revela el estado de desesperación en que se encuentran algunos sectores de los intelectuales burgueses, que no pueden ver con despejado optimismo el 
futuro y tratan de imponer la originalidad de la filosofía latinoamericana a través de filosofías que ya no son nada originales y que han demostrado incluso su total ineficacia práctica con la derrota del fascismo y que siempre estarán condenadas al fracaso porque se oponen al amor que sienten todos los pueblos del mundo por la paz y la democracia. Las filosofías de la fuerza se verán siempre refutadas por la fuerza de la filosofía, que hace del humano un ser racional y por tanto defensor siempre de los principios genuinamente humanos. Aquel que busque la razón de ser del pensamiento filosófico latinoamericano en la irracionalidad se dirige a un callejón sin salida, porque el irracionalismo por esencia constituye la negación de la propia filosofía.

Los que por otro lado piensan que "la filosofía latinoamericana no se ha realizado aún por carencia de suficiente profesionalismo" (Villoro, 1982. p. 34) como el mexicano Luis Villoro y el venezolano Alejandro Rossé y reclaman un tecnicismo conceptual sistémico, olvidan que Tales, Heráclito, Pitágoras o Parménides no poseían un aparato conceptual elaborado y amplio, sin embargo, nadie pone en duda su digno lugar en la historia de la filosofía. Entonces, ¿por qué hemos de exigir una exquisita rigurosidad y un perfeccionismo técnico en un saber tan generalizador como el filosófico?

Los defensores de esta "filosofía profesional", quienes también desean que no se corresponda con los "centros de poder" aspiran a que esta sea desarrollada por equipos de especialistas cuya exclusiva labor sea el análisis de dichos temas, lo cual resulta muy encomiable desde el punto de vista de que toda actividad intelectual reclama hoy en día en verdad la labor colectiva que deja para el pasado la labor de los pensadores aislados. Sin embargo, pasan por alto que una genuina filosofía del futuro no puede circunscribirse a la actividad de reducidas elites de estudiosos separados de los intereses y aspiraciones de los sectores populares. De ahí la imperiosa necesidad de que la filosofía se divulgue entre ellos y se retroalimente en ellos, de que en interacción dialéctica enseñe y aprenda en ellos. Pero eso no puede hacerlo una filosofía que no presente con claridad diáfana sus objetivos ideológicos o una filosofía que tema al pueblo o tenga el falso temor de vulgarizarse por vincularse con él. Precisamente estas son características muy propias del actual pensamiento filosófico latinoamericano, que, impregnado de consideraciones abstractas sobre el desarrollo social, evade la búsqueda de las causas reales de los problemas de los latinoamericanos, en las raíces socioeconómicas y políticas de su ser. Esta 
es la razón por la cual tomó tanto auge a partir de mediados del siglo xx la llamada cuestión antropológica en la filosofía latinoamericana, que se diluye en cuestionar y debatir simplemente la esencia de lo humano apoyándose en Kierkegaard, Jasper, Heidegger, Cassirer, Ortega y Gasset o Scheler, entre otros.

Muchos de los intelectuales latinoamericanos coinciden en la ignorancia que se tiene sobre la esencia del ser humano y en la necesidad de abordarlo a la luz de una antropología generalizadora, "desideologizada" y desvinculada de los problemas socioeconómicos que lo envuelven. Claro ejemplo sintentizador de estas posiciones lo brindó el costarricense Alejandro Aguilar Machado (1953) cuando afirmó:

El problema agudo que afrontamos, no es como lo piensan quienes solo contemplan al hombre y su mundo a sus circunstancias desde la periferia económica. Ni tampoco es solo jurídico, de simples esferas de carácter internacional, unidas a los procesos evolutivos del jus gentium. El problema, por su fondo mismo, después de una sabia y honesta perforación, deviene filosófico, neta y claramente filosófico. El destino del hombre, la única clave con que se puede descifrar el destino del universo se ha perdido y continúa perdido. Los ingentes esfuerzos empeñados en el conocimiento del cosmosfísico y el mismo proceso dialéctico de las ideas han absorbido las actividades cognoscentes, en forma tal, que la filosofía, que nos debe confrontar con nuestro propio hacer, haciéndonos reflexionar sobre ello, lleva perdida una dirección acertada y eficaz. Enredase en la maraña de diversas ideologías, envuélvase en la tela de múltiples y artificiosas dialécticas, sin poder rebasar la recia construcción de sistemas, no pocas veces puesto entre sí (p. 24).

Por tanto, la única solución que ven al problema se limita a la consideración de que "el verdadero fin y propósito en el problema del hombre es lo ético" (Domínguez, 1953, p. 40) como asegura el panameño Diego Domínguez Caballero. De esta forma se revela la postura evasiva de los que disuelven en abstracciones vacías de contenido, los conflictos concretos del ser humano y en particular del latinoamericano. Cargados de escepticismo y de desconfianza en la posibilidad de un mejoramiento de las circunstancias que obstaculizan su realización plena, tratan de inculparlo y a la compleji- 
dad de sus relaciones. Temen a la ideología y piensan que en el terreno de la ética se liberan de ella, como si pudiera existir una moral por encima de las ideologías, una moral abstracta como la que buscaba Feuerbach y que Engels refutó al indicar que "sirven para todos los tiempos, todos los pueblos y todas las circunstancias, razón por la cual no es aplicable nunca ni en parte alguna, resultando tan impotente frente a la realidad como el imperativo categórico de Kant” (Engels, 1973. p. 406), demostrando así científicamente el carácter clasista y por tanto histórico de toda moral. Pero como ya es común, los rastreadores de la filosofía latinoamericana no se percatan de las profundas huellas que dejan las diferencias de clases y su necesaria lucha en el terreno social, ventean los conceptos pero no dirigen la mirada hacia abajo, hacia la realidad que los determina.

Sin embargo, aun así habrá quien se lamente de que la filosofía latinoamericana posea una excesiva inclinación hacia los problemas políticos (Sánchez Reulet, 1953, p. 143), demostrando tal vez el disgusto que pueda causarle el hecho de que los más grandes pensadores de nuestro continente, en vez de construir complejos sistemas filosóficos, han sido abanderados del pensamiento y la acción como lo demuestra la obra de José Martí. Por doquier emerge la marcada intención de "desideologizar" la filosofía latinoamericana y de convertirla en estéril actividad académica, aislada de las inquietudes sociales.

Sobre esta problemática la posición de Zea, aunque coincide en cuanto a la abierta carga ideológica de la filosofía latinoamericana que la distingue de las demás, es algo diferente por lo que afirma: "la filosofía funciona como ideología, da razones, no del ser o los entes, como algunas expresiones de la filosofía occidental sino del orden político y social latinoamericano"(Zea, 1969, p. 39). En verdad no se lamenta, como otros, de la propensión ideológica del pensamiento filosófico latinoamericano, a la vez que con razón indica el sustrato ideológico que han tenido todos los sistemas filosóficos de la humanidad. Por esto considera que aunque no tengamos grandes figuras universales reconocidas, nuestra filosofía en este sentido no es inferior a las demás (Zea, 1969, pp. 40-42). Esta concepción sobre el necesario vínculo ideológico y la función política de la filosofía la ratificó Zea en las conversaciones sostenidas con él en sus visitas al Instituto de Filosofía de la Academia de Ciencias de Cuba. 
Si la filosofía latinoamericana ha inclinado siempre la balanza hacia el lado de la ideología en detrimento del aspecto científico, ha sido porque las condiciones históricas han favorecido tal inclinación; no es por una simple cuestión vocacional o temperamental, como en ocasiones algunos historiadores pretenden atribuirnos. Nuestras circunstancias de dependencia económica, política y social, desde la conquista hasta el presente, nos ha llevado a plantearnos, junto a los amplios problemas de la relación entre el ser y el pensar, ante todo el acucioso dilema de nuestra razón de ser, del régimen social que debíamos tener. La historia de la filosofía muestra cómo las grandes preocupaciones sociopolíticas han abundado más en los períodos y en los lugares en que más transformaciones sociales han requerido. No se observa la misma carga ideológica en los presocráticos que en la convulsa época de Platón y Aristóteles, como tampoco se encuentra en Descartes comparado con los pensadores del revolucionario siglo de la ilustración francesa. Por tanto, no nos debe extrañar que en una América Latina siempre necesitada de revoluciones que la emancipen plenamente, la filosofía posea tal carácter.

A la vez resulta insostenible la diferenciación que establece Miró Quesada entre la filosofía europea y la latinoamericana, atribuyéndole a la primera la particularidad de haberse constituido en función de la actividad política, mientras que por el contrario en la segunda, la praxis política buscó acogerse a cualquier doctrina metafísica, o por lo menos filosófica, para justificarse, En general, la política no derivará teóricamente del pensamiento filosófico sino más bien, buscando justificación, se refugiará en una determinada doctrina filosófica. En los casos que la acción política parece anticipada por una base filosófica previa, como podía ser en el movimiento independentista y, en algunas ocasiones, el marxista, se hace patente una distorsión teórica, producida no solo por una limitada comprensión de las doctrinas básicas, sino sobre todo por el hecho de que las teorías aparecen impuestas por la moda europea y no han sido el producto de la creación racional que correspondía al desarrolla natural de una colectividad (Miró Quesada, 1968, p. 188).

Esta es una forma muy sutil de decir que los latinoamericanos no son capaces de pensar con cabeza propia y que han actuado careciendo de una fundamentación legítima de su acción, como si tal actuación fuese posible alguna vez, pues, por mucho que nutra el ser humano su intelecto con 
las doctrinas de otros pensadores, necesariamente esas ideas atravesarán el prisma de su conciencia individual y colectiva emanada del medio que las conforman y sustantivada por infinitos elementos exógenos y endógenos, de ahí que al concordar su praxis con los principios que sostiene su concepción del mundo debe ser tomada como válida y por tanto auténtica.

Ahora bien, si lo que se pretende es prevenir de antemano la fundamentación filosófica de la acción por temor a inferencias “extrañas", sépase que resultará siempre estéril, ya que jamás podremos aislar al ser humano en una urna de cristal que lo separe del radio de acción de las ideas y fundamentos teóricos vengan de donde vengan. Realmente Miró quiso tomar precauciones frente al marxismo. Le ha preocupado la imposición de esa "moda europea", revelando una vez más la presencia antimarxista inherente a todas estas disquisiciones, que presentan la fachada de evitar la imitación de lo extranjero. Sin embargo, ante todo debemos cuestionarnos ¿por qué razón hemos de temer seguir los buenos ejemplos?, ¿por qué rehuir los modelos de desarrollo y de pensamiento que han demostrado su eficacia?, ¿No se corre el peligro de tomar rumbos inseguros que en vez de superar limiten mucho más nuestra contradicción de países atrasados? Tal vez ese elemento no se tuvo presente, ni siquiera por el propio Zea (1976) cuando señalaba :

Si hemos de crear una filosofía, como expresión de una cultura y una
sociedad libre, una filosofía que sea expresión de nuestra realidad y
sirva a la satisfacción de sus intereses y la solución de sus problemas,
tendremos que hacer lo mismo que hacen los grandes modelos, los
que han sido nuestros arquetipos, esto es, ponernos pura y simple-
mente a la tarea de su realización, pero sin pretender semejarnos a
ningún modelo, pero tampoco pretendiendo ser epígonos de sus
expresiones. (p.223).

Pero ¿podrá cualquier filosofía actual prescindir en verdad de tales modelos, aun cuando se trate de una filosofía que pretenda ser renovadora? El punto de partida sociopolítico de toda filosofía que ha tratado de proyectarse al futuro ha sido necesariamente la forma más desarrollada de su presente histórico, de ahí que el ideal de los enciclopedistas franceses haya partido de la avanzada Inglaterra país este que Marx tomaría también con modelo de análisis en su obra cumbre El capital para desentrañar las contradicciones 
inherentes al modo de producción capitalista y demostrar científicamente su necesaria superación por el socialismo.

Resultaba un equívoco en el pasado siglo xx igualar como modelo de desarrollo a los Estados Unidos y a la Unión Soviética como se observaba en algunos propugnadores de una filosofía latinoamericana auténtica en aquellos años de guerra fría, sin destacar las radicales diferencias que existían entre ambos países.

El imperialismo norteamericano alcanzó su poderío precisamente a expensas de las riquezas de los países latinoamericanos y de otros de África y Asia. Si bien en ocasiones parece restablecerse de sus frecuentes crisis, que se manifiestan en todas sus esferas, a la larga vuelve a caer en ellas. No se debe tomar como modelo una sociedad consumista que solo pretende asegurar un decoroso nivel de vida a determinados sectores sociales, incluso como la clase media, tal y como sostuvo Barack Obama en sus campañas electorales.

Los modelos de desarrollo, si es que acaso se asumen algunas características de algunos países, por lo nefasto que siempre resulta copiar modelos, deben ser tomados teniendo en consideración las circunstancias históricas específicas de desarrollo de cada país, pero no de lo retrógrado.

La filosofía auténticamente latinoamericana no debe rehuir lo que a algunos les pueda parecer extraño, sino más bien debe realizarse en una filosofía que día tras día demuestre su incuestionable autenticidad y universalidad, al corresponderse con las demandas de los tiempos en el presente siglo XXI. Una filosofía auténtica no debe ser exclusiva de un país o una región o cultura como la latinoamericana, sino que debe ser válida a todos los pueblos del mundo en tanto que deba recoger la herencia filosófica progresista de cada país incorporándolo al acervo cultural de toda la humanidad. De ahí que constituye una tarea actual investigar los valores de ese pasado y presente filosófico latinoamericano no para atribuirle una exclusividad histórica que no tendrá filosofía alguna, sino para justipreciarla y darle su merecido lugar en la historia universal de la filosofía.

La filosofía latinoamericana ha sido auténtica en tanto ha coincidido con la línea ascendente de la filosofía universal, que en el caso del pensamiento burgués llega el momento en que esa clase social desempeñó un papel progresista, momento este en que no coinciden la historia de este continente y la historia universal, razón por la cual se observan filosofías como 
el positivismo, que ya universalmente marcaban el inicio de la decadencia de la filosofía contemporánea y aún desempeñan una función progresista por regla general en América Latina dadas sus condiciones específicas de atraso socioeconómico.

La autenticidad de la filosofía latinoamericana se demuestra al constatarse su coincidencia con las exigencias del desarrollo histórico en cada período, por eso ha sido autentica y lo será cada vez más en la misma medida en que vaya dejando atrás el andamiaje insostenible de la filosofía metafísica contemporánea y realice su genuino ser en una filosofía más realista y optimista. 

Capítulo V

BIBLIOTECA

(1․․ COLOMBIANA 
